\title{
Valor Nutritivo de Silagem de Capim-Elefante (Pennisetum purpureum Schum.) com Diferentes Níveis de Casca de Café
}

\section{Alexandre Lima de Souza1, Fernando Salgado Bernardino², Rasmo Garcia ${ }^{3}$, Odilon Gomes Pereira $^{3}$, Fernanda Cipriano Rocha ${ }^{4}$, Aureliano José Vieira Pires ${ }^{5}$}

\begin{abstract}
RESUMO - Avaliaram-se os efeitos de diferentes níveis de casca de café $(0,8,7 ; 17,4 ; 26,1$; e 34,8 $\mathrm{kg}$ de casca de café/100 kg de forragem fresca) sobre a composição bromatológica e a digestibilidade in vitro da matéria seca (DIVMS) da silagem de capim-elefante. Na produção das silagens foram utilizados 15 silos cilíndricos de PVC com de 0,25 m de diâmetro e 0,75 m de altura, adotando-se uma compactação de $550 \mathrm{~kg} / \mathrm{m}^{3}$. O teor de MS aumentou em função dos níveis crescentes de casca, estimando-se acréscimo de $0,54 \%$ por unidade de casca de café adicionada. Os valores de $\mathrm{pH}$ foram menores para as silagens com casca, estimando-se valor mínimo de 3,78 para o nível de $26,87 \%$ de casca. O teor de PB $(8,9 \%)$ da silagem sem casca de café foi inferior aos $11,1 \%$ verificados na forragem fresca e nas silagens contendo casca de café. A adição de casca de café ao capim-elefante resultou em silagens com menores teores de fibra em detergente neutro e hemicelulose, ao mesmo tempo em que os teores de lignina das silagens foram aumentados. Foi estimada uma redução de apenas 0,14\% na DIVMS das silagens por unidade de casca de café adicionada. A casca de café, em níveis iguais ou superiores a 17,4 kg de casca/ $100 \mathrm{~kg}$ de forragem fresca, revelou ser um bom aditivo para a ensilagem de capim-elefante com alto teor de umidade.
\end{abstract}

Palavras-chave: aditivo, composição bromatológica, digestibilidade, $\mathrm{pH}$, resíduo agroindustrial

\section{Nutritive Value of Elephantgrass (Pennisetum purpureum Schum.) Silage with Different Levels of Coffee Hulls}

\begin{abstract}
One experiment was conducted to evaluate the effects of five levels of coffee hulls $(0,8.7,17.4,26.1$, and $34.8 \mathrm{~kg} /$ $100 \mathrm{~kg}$ of fresh forage) on the bromatologic composition and IVDMD of elephantgrass silage. Fifteen plastic silos measuring .25 of diameter x .75 of height were used. In the ensiling process the forage received a pressure of $550 \mathrm{~kg} / \mathrm{m}^{3}$. The results showed that the percentage of dry matter increased linearly with increasing of coffee hulls. It was estimated an increasing of .54\% for each unit of coffee hulls added. The $\mathrm{pH}$ value was inferior for silage with coffee hulls. It was estimated a minimum value of 3.78 for the level $26.87 \%$ of coffee hulls. The content of CP of the silage without coffee hulls (8.9\%) was inferior to (11.1\%) found in the fresh forage and silages with coffee hulls. The IVDMD value was reduced according to crescent levels of coffee hulls. It was estimated a decreasing of .14\% for each unit of coffee hulls added. It is possible to conclude that the addition of coffee hulls on level of $17.4 \mathrm{~kg}$ of coffee hulls/100 $\mathrm{kg}$ of fresh forage showed be a good additive for ensiling elephantgrass with high moisture content.
\end{abstract}

Key Words: additive, agroindustrial residue, bromatologic composition, digestibility, $\mathrm{pH}$

\section{Introdução}

Nos últimos anos, tem havido crescente interesse na utilização de gramíneas forrageiras para produção de silagens. Dentre estas gramíneas, o capim-elefante tem sido indicado, principalmente, por sua alta produção de matéria seca e bom valor nutritivo. Entretanto, a presença de alto teor de umidade no momento ideal para o corte, baixo teor de carboidratos solúveis e ainda alta capacidade tampão das gramíneas em geral, são fatores que inibem adequado processo fermentativo, dificul- tando a confecção de silagens de boa qualidade (McDonald, 1981; Lavezzo, 1985).

Além de prejudicar a fermentação, a ensilagem de plantas com alto teor de umidade resulta na produção de elevadas quantidades de efluente, o qual transporta em sua solução nutrientes altamente digestíveis. O efluente contém grande quantidade de compostos orgânicos como açúcares, ácidos orgânicos, proteínas e outros componentes provenientes do material ensilado, constituindo uma fonte nutricional para os diferentes microrganismos saprófitos que vivem em córregos e rios (McDonald et al., 1981).

\footnotetext{
1 Zootecnista, MS, DZO/UFV. E.mail: alex-ls@bol.com.br

2 Zootecnista, DZO/UFV.

${ }^{3}$ Professor do Departamento de Zootecnia, UFV. Bolsista do CNPq.

${ }^{4}$ Zootecnista, MSc, DZO/UFV.

${ }^{5}$ Professor do Departamento de Tecnologia Rural e Animal - UESB.
} 
$\mathrm{Na}$ tentativa de aumentar o teor de matéria seca e a concentração de carboidratos solúveis de gramíneas, como o capim-elefante, no momento da ensilagem, o emurchecimento do material e o uso de aditivos são técnicas que têm sido recomendadas (Tosi et al., 1995; Tosi et al., 1999). Todavia, a perda de umidade por exposição ao sol nem sempre é satisfatória, pois o diâmetro dos colmos do capimelefante dificulta o trânsito de água do interior para a periferia destes (Tosi et al., 1999). O emurchecimento do capim aumenta o tempo entre o corte e a vedação do silo, resultando em maiores perdas devido ao processo respiratório e atividade proteolítica da planta, que resultam na redução de substratos fermentáveis e aumento do nitrogênio não-protéico (McDONALD, 1981). Além disso, a adoção desta prática eleva os gastos com mão-de-obra.

Com a finalidade de melhorar o processo de fermentação e a qualidade da silagem de gramíneas, vários aditivos têm sido testados. Dentre estes, os aditivos absorventes, caracterizados por reduzir ou eliminar a produção de efluente do silo (Wilkinson, 1998), podem assumir um importante papel na confecção de silagens de gramíneas com alta umidade.

A casca de café, resíduo proveniente do beneficiamento do grão, por apresentar elevado conteúdo de matéria seca e propriedades higroscópicas, pode atuar como aditivo absorvente. Este resíduo apresenta ainda teor de carboidratos solúveis próximo a $17 \%$ (Souza et al., 2001), o que poderá favorecer o processo fermentativo do material ensilado.

Objetivou-se, portanto, com este experimento avaliar os efeitos da adição de diferentes níveis de casca de café sobre a composição químicobromatológica, $\mathrm{pH}$ e digestibilidade in vitro da matéria seca (DIVMS) da silagem de capim-elefante.

\section{Material e Métodos}

O experimento foi conduzido no Departamento de Zootecnia da Universidade Federal de Viçosa, em Viçosa, MG. A forrageira utilizada foi o capim-elefante (Pennisetum purpureum Schum.) cultivar Cameroon proveniente de capineira já estabelecida, onde são incorporados somente adubos orgânicos, esterco de bovinos, durante o ano. O capim foi cortado manualmente, rente ao solo, no dia seis de junho de 2000 quando apresentava altura média de 1,80 m. Em seguida, foi picado em partículas de aproximadamente $5 \mathrm{~cm}$, em máquina ensiladeira estacionária.
A casca de café, adquirida de indústria beneficiadora localizada no sul do Estado de Minas Gerais, foi moída em moinho tipo martelo com peneira de $2 \mathrm{~mm}$ e adicionada à forragem recém-picada em cinco níveis: $0 ; 8,7 ; 17,4 ; 26,1$ e $34,8 \mathrm{~kg}$ de MN/100 kg de forragem verde, com três repetições. Para confecção das silagens foram utilizados silos de PVC com $0,25 \mathrm{~m}$ de diâmetro e $0,75 \mathrm{~m}$ de altura, dotados de drenos para coleta de efluente. Em cada silo foi colocado 20,2 kg da mistura fresca, adotando-se uma compactação de $550 \mathrm{~kg} / \mathrm{m} 3$. Após o enchimento, os silos foram vedados utilizando-se tampa de madeira revestida por plástico e fita plástica adesiva. No sexto dia após o enchimento procedeu-se a vedação dos drenos existentes na parte inferior de cada silo.

A composição químico-bromatológica e a digestibilidade in vitro da matéria seca do capimelefante e da casca de café utilizadas são apresentadas na Tabela 1.

Após 64 dias de ensilagem, procedeu-se à abertura dos silos, coletando-se em seguida amostras referentes a cada unidade experimental, após a homogeneização das mesmas. As amostras foram colocadas em sacos plásticos etiquetados e armaze-

Tabela 1 - Composição químico-bromatológica e digestibilidade in vitro da matéria seca (DIVMS) do capim-elefante e da casca de café

Table 1 - Chemical-bromatologic composition and in vitro dry matter digestibility (IVDMD) of elephantgrass and coffee hulls

\begin{tabular}{|c|c|c|}
\hline $\begin{array}{l}\text { Itens } \\
\text { Item }\end{array}$ & $\begin{array}{c}\text { Capim-elefante } \\
\text { Elephantgrass }\end{array}$ & $\begin{array}{c}\text { Casca de café } \\
\text { Coffee hulls }\end{array}$ \\
\hline $\operatorname{MS}(\%)$ & 14,45 & 81,64 \\
\hline $\begin{array}{l}\mathrm{PB}(\% \mathrm{MS}) \\
C P(\% D M)\end{array}$ & 11,10 & 9,28 \\
\hline $\begin{array}{l}\text { NIDA/NT }{ }^{1}(\%) \\
I A D N / T N(\%)\end{array}$ & 6,66 & 25,54 \\
\hline $\begin{array}{l}\mathrm{FDN}(\% \mathrm{MS}) \\
N D F(\% D M)\end{array}$ & 69,64 & 52,74 \\
\hline $\begin{array}{l}\mathrm{FDA}(\% \mathrm{MS}) \\
A D F(\% D M)\end{array}$ & 43,52 & 39,85 \\
\hline $\begin{array}{l}\text { Lignina }(\% \mathrm{MS}) \\
\text { Lignin }(\% D M)\end{array}$ & 6,73 & 8,69 \\
\hline $\begin{array}{l}\mathrm{CAD}^{2}(\% \mathrm{MS}) \\
A D C(\% M S)\end{array}$ & 19,48 & 25,97 \\
\hline $\begin{array}{l}\text { DIVMS (\% MS) } \\
I V D M D(\% D M)\end{array}$ & 66,55 & 54,76 \\
\hline
\end{tabular}

\footnotetext{
${ }_{1}$ Nitrogênio insolúvel em detergente ácido (na base do nitrogênio total).

${ }_{2}^{1}$ Acid detergent insoluble nitrogen (as total nitrogen basis).

2 Carboidratos ácido digeríveis.

${ }^{2}$ Acid digestible carbohydrate.
} 
nadas em freezer para posteriores análises. Os valores de matéria seca (MS), proteína bruta (PB), fibra em detergente neutro (FDN), fibra em detergente ácida(FDA), hemicelulose, lignina, $\mathrm{pH}$ e digestibilidade in vitro da matéria seca (DIVMS), foram determinados conforme procedimentos descritos por Silva (1990). Para determinação da DIVMS, utilizou-se o método de duas etapas (96h de incubação). Os teores de carboidratos ácidos digeríveis (CAD), nos quais estão contidos amido, monossacarídios e dissacarídios, foram quantificados conforme procedimentos relatados por Silva (1990). Já os teores de nitrogênio insolúvel em detergente ácido (NIDA) foram determinados de acordo com os procedimentos descritos por Licitra et al. (1996), sendo expressos como porcentagem do nitrogênio total (NIDA/NT).

O delineamento experimental utilizado foi inteiramente casualizado, com três repetições, sendo os resultados interpretados por meio das análises de variância e de regressão. A escolha do melhor modelo foi feita com base no coeficiente de determinação e na significância dos coeficientes de regressão, utilizandose o teste " $t$ " de Student, a 1\% de probabilidade. As análises estatísticas foram realizadas utilizando-se o Programa SAEG, versão 7.1 (UFV, 1997).

\section{Resultados e Discussão}

Os teores de MS e pH das silagens são apresentados na Tabela 2 . Ao proceder ao estudo da regressão polinomial, verificou-se efeito linear $(\mathrm{P}<0,01)$ dos níveis de casca sobre o teor médio de MS das silagens, estimando-se acréscimo de $0,54 \%$ no teor de MS por unidade de casca de café adicionada. Estes aumentos foram superiores aos obtidos por Ferrari Jr. \& Lavezzo (2001), que verificaram incrementos de $0,45 \%$ no teor MS da silagem de capim- elefante por unidade de farelo de mandioca adicionada a forrageira que apresentava $18,65 \%$ de MS, no momento da ensilagem.

Ao ensilar capim-elefante cv Taiwan A-148 ( $15,9 \%$ de MS) com 20,30 e $40 \%$ de sabugo de milho ou após sofrer emurchecimento por 12 ou $24 \mathrm{~h}$ Tosi et al. (1999) encontraram valores de 25,27; 29,41; 33,$41 ; 20,64$ e $31,5 \%$ de MS para as respectivas silagens. No presente experimento os respectivos valores de MS poderiam ser obtidos com a adição de 18,$59 ; 26,21 ; 33.58 ; 10,07$ e 30,06\% de casca de café, estimados pela equação de regressão. Estes dados indicam que a casca de café mostrou-se um aditivo eficiente em elevar o teor de MS de silagens de capim-elefante, produzidas com alto teor de umidade. Tal fato pode ser atribuído, entre outros, ao alto teor de matéria seca da casca de café $(81,6 \%)$, bem como à sua boa capacidade em reter umidade.

Ao adicionar $17,4 \%$ de casca estimou-se pela equação $\hat{\mathrm{Y}}=15,1707+0,543111^{* *} \mathrm{X}\left(\mathrm{r}^{2}=0,99\right) \mathrm{um}$ teor de $24,6 \%$ de MS, acima dos $20 \%$ relatado por McDonald (1981) para preservação de gramíneas na forma de silagem. Semelhante ao observado neste experimento Loures (2000), constataram que a silagem de capim-elefante com $25 \%$ de MS além de não ter produzido efluente apresentou ainda odor agradável e coloração característica.

O comportamento dos valores de $\mathrm{pH}$ das silagens é mostrado na Figura 1. Verificou-se efeito quadrático $(\mathrm{P}<0,01)$ dos níveis de casca, estimando-se valor mínimo de $\mathrm{pH}$ igual a 3,78 para o nível de $26,87 \%$ de casca de café, segundo a equação de regressão $\hat{\mathrm{Y}}=15,1707+0,543111^{* *} \mathrm{X}\left(\mathrm{r}^{2}=0,99\right)$. As silagens com níveis de 0 e $8,7 \%$ de casca apresentaram baixos teores de MS, que associados aos maiores valores de pH registrados, podem ter contribuído para a ocorrência de uma fermentação inadequada, percebida

Tabela 2 - Teores médios de matéria seca (MS) e pH registrados para as diferentes silagens com suas respectivas equações de regressão

Table 2 - Average contents of dry matter (DM) and $\mathrm{pH}$ of the silages with the respective regression equations

\begin{tabular}{|c|c|c|c|c|c|c|}
\hline \multirow[t]{3}{*}{$\begin{array}{l}\text { Item } \\
\text { Item }\end{array}$} & \multicolumn{5}{|c|}{$\begin{array}{l}\text { Silagens }^{1} \\
\text { Silages }\end{array}$} & \multirow[t]{3}{*}{$\begin{array}{l}\text { Equação de regressão } \\
\text { Regression equations }\end{array}$} \\
\hline & \multicolumn{5}{|c|}{$\begin{array}{l}\text { Níveis de casca de café }(\%) \\
\text { Levels of coffee hulls (\%) }\end{array}$} & \\
\hline & 0 & 8,7 & 17,4 & 26,1 & 34,8 & \\
\hline MS \% (DM\%) & 15,06 & 20,46 & 24,04 & 29,24 & 34,30 & $\hat{\mathrm{Y}}=15,1707+0,54311 * * \mathrm{X}\left(\mathrm{r}^{2}=0,99\right)$ \\
\hline $\mathrm{pH}$ & 4,46 & 3,94 & 3,87 & 3,87 & 3,98 & $\hat{\mathrm{Y}}=4,4216-0,0558^{*} * \mathrm{X}+0,00126^{* *} \mathrm{X}^{2}\left(\mathrm{r}^{2}=0,95\right)$ \\
\hline
\end{tabular}

R. Bras. Zootec., v.32, n.4, p.828-833, 2003 
por forte odor desagradável, semelhante a fermentação acética. Além do alto teor de MS, a concentração de carboidratos solúveis da casca, 17,1\% (Souza et al., 2001), também pode contribuir para abaixamento do $\mathrm{pH}$, uma vez que estes são os principais substratos utilizados pelas bactérias produtoras de ácido lático (McDonald, 1981; Rotz \& Muck, 1994). Os maiores teores de carboidratos ácidos digeríveis determinados na casca de café em relação ao capim-elefante (Tabela 1) é indicativo de que este resíduo pode contribuir para melhorar o padrão de fermentação das silagens de capins.

O valor de PB da silagem sem casca de café foi próximo ao registrado por Tosi et al. (1999) na silagem do cv. Taiwan A-148 que foi de $8,57 \%$ de PB. As silagens com casca de café apresentaram maiores teores de $\mathrm{PB}$ que a silagem sem casca de café, a qual teve seu teor médio de PB reduzido de 11,1 para $8,9 \%$, quando comparado à forrageira no momento da ensilagem. $\mathrm{O}$ comportamento dos teores de PB das silagens é mostrado na Figura 2. Observou-se efeito quadrático, $\hat{\mathrm{Y}}=8,79914+0,23139^{* *} \mathrm{X}-0,00555^{* * *} \mathrm{X}^{2}\left(\mathrm{R}^{2}=0,90\right)$, com adição dos níveis de casca de café, estimando-se valor máximo de 11,21 para o nível de 20,82\% de casca de café.

O baixo teor de PB observado na silagem testemunha pode ser atribuído à perda de compostos nitrogenados solúveis no efluente. Segundo McDonald (1981), em silagens com $85 \%$ de umidade, a perda de MS na forma de efluente pode exceder a $9 \%$. Já para a silagens com níveis superiores a $20,82 \%$ de casca, a queda no teor de PB pode ter sido causada por um efeito de diluição, pois a casca de café apresentou

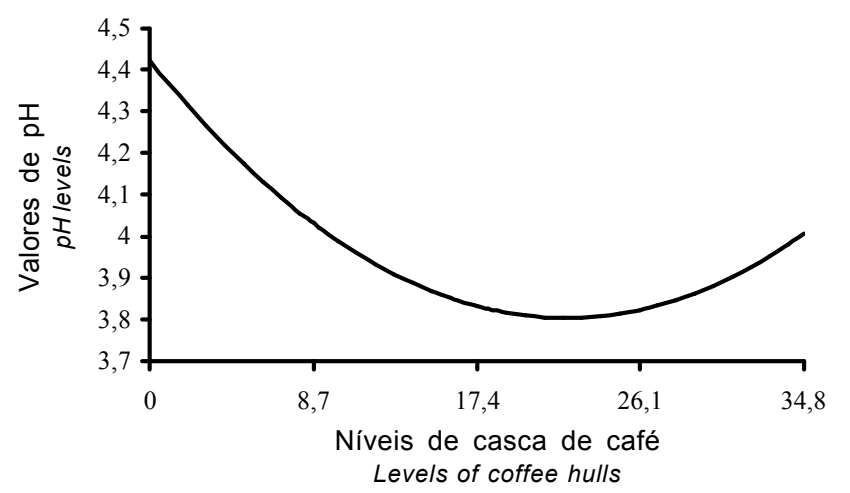

Figura 1 - Estimativa dos valores de $\mathrm{pH}$ das silagens em função de diferentes níveis de casca de café.

Figure 1 - Estimate $\mathrm{pH}$ values in function of the levels of coffee hulls in the elephantgrass silages. menor teor de $\mathrm{PB}$ em relação à forrageira (Tabela 1). Para as silagens com nível igual ou superior a 17,4\% de casca de café que apresentaram teores acima de $24 \%$ de MS não foi constatado, através de observações visuais, sinais de produção de efluente. Além do que, nesta silagens os teores de MS e de $\mathrm{pH}$, junto com observações de odor agradável e da ausência de bolores visíveis foram indicativos de silagens bem preservadas.

A análise de regressão revelou efeito linear dos níveis de casca de café sobre os teores de NIDA/NT das silagens. O aumento nos teores de NIDA/NT pode ser explicado pelos maiores valores de NIDA/ NT da casca de café em relação ao capim-elefante no momento da ensilagem, conforme mostrado na Tabela 1. Os valores médios, estimados em função dos níveis de casca de café $(0 ; 8,7 ; 17,4 ; 26,1$ e $34,8 \%$ ) foram de 6,$40 ; 9,23 ; 12,05 ; 14,88$ e $17,70 \%$, respectivamente.

O aumento no teor de NIDA não é desejável, pois o nitrogênio retido na fibra em detergente ácido não é aproveitado pelas bactérias ruminais (Van Soest \& Mason, 1991; Licitra et al., 1996). Entretanto, ao se estimar a quantidade de nitrogênio disponível (ND = NT - NIDA), verificou-se valores médios de ND de 1,$32 ; 1,51 ; 1,57 ; 1,51$ e 1,33 , para os níveis de $0 ; 8,7$; 17,$4 ; 26,1$ e $34,8 \%$ de casca de café, respectivamente. Além do aumento no teor de PB das silagens observa-se também aumento na quantidade de PB disponível (PBD) para síntese microbiana, observando valores mínimos e máximos de 8,24 e de $9,8 \%$, para as silagens sem casca de café e com $17,4 \%$ de casca, respectivamente. Isso demonstra que a adição de casca de café ao capim-elefante, com $14,5 \%$ de

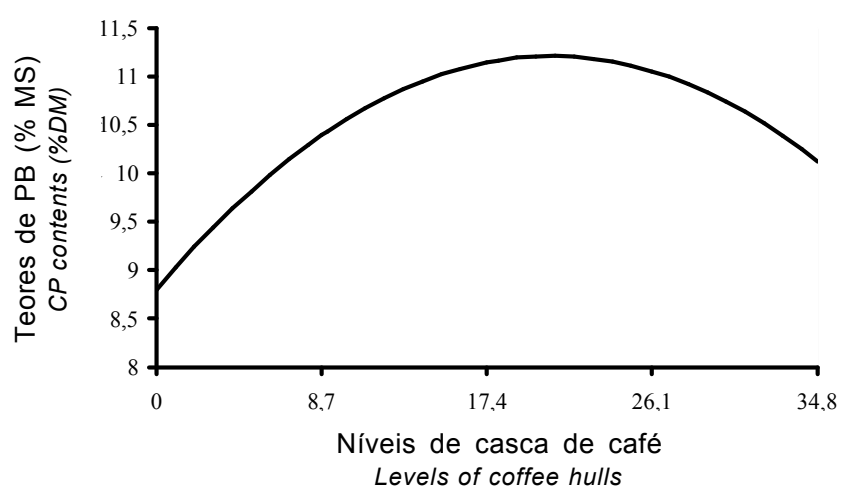

Figura 2 - Estimativa dos teores de proteína bruta (PB) das silagens em função de diferentes níveis de casca de café.

Figure 2 - Estimate crude protein $(C P)$ contents in function of the levels coffee hulls in the elephantgrass silages.

R. Bras. Zootec., v.32, n.4, p.828-833, 2003 
Tabela 3 - Teores médios de fibra em detergente neutro (FDN), fibra em detergente ácido (FDA), hemicelulose e lignina registrados para as diferentes silagens com suas respectivas equações de regressão

Table 3 - Average contents of neutral detergent fiber (NDF), acid detergent fiber (ADF), hemicellulose and lignin of the silages with respective regression equations

\begin{tabular}{|c|c|c|c|c|c|c|}
\hline \multirow[t]{3}{*}{$\begin{array}{l}\text { Item } \\
\text { Item }\end{array}$} & \multicolumn{5}{|c|}{$\begin{array}{l}\text { Silagens }^{1} \\
\text { Silages }\end{array}$} & \multirow[t]{3}{*}{$\begin{array}{l}\text { Equação de regressão } \\
\text { Regression equations }\end{array}$} \\
\hline & \multicolumn{5}{|c|}{$\begin{array}{l}\text { Níveis de casca de café (\%) } \\
\text { Levels of coffee hulls (\%) }\end{array}$} & \\
\hline & 0 & 8,7 & 17,4 & 26,1 & 34,8 & \\
\hline $\begin{array}{l}\mathrm{FDN}(\%) \\
N D F(\%)\end{array}$ & 72,89 & 65,60 & 62,66 & 60,52 & 61,74 & $\hat{\mathrm{Y}}=70,16-0,314592 * * \mathrm{X}\left(\mathrm{r}^{2}=0,76\right)$ \\
\hline $\begin{array}{l}\mathrm{FDA}(\%) \\
A D F(\%)\end{array}$ & 46,61 & 42,26 & 42,53 & 41,76 & 44,12 & $\hat{\mathrm{Y}}=46,3877-0,50123 * * \mathrm{X}+0,01307 * * \mathrm{X}^{2}\left(\mathrm{r}^{2}=0,90\right)$ \\
\hline $\begin{array}{l}\text { Hemicelulose (\%) } \\
\text { Hemicellulose (\%) }\end{array}$ & 26,28 & 23,34 & 20,13 & 18,76 & 17,63 & $\hat{\mathrm{Y}}=25,7520-0,26845 * * \mathrm{X}\left(\mathrm{r}^{2}=0,97\right)$ \\
\hline $\begin{array}{l}\text { Lignina (\%) } \\
\text { Lignin (\%) }\end{array}$ & 5,71 & 6,69 & 7,81 & 8,28 & 9,02 & $\hat{\mathrm{Y}}=5,86219+0,0,09432 * * \mathrm{X}\left(\mathrm{r}^{2}=0,98\right)$ \\
\hline
\end{tabular}

MS, no momento da ensilagem, contribuiu de forma positiva sobre os compostos nitrogenados das silagens.

Os valores médios observados de FDN para as diferentes silagens encontram-se na Tabela 3. Ao proceder o estudo da regressão polinomial, verificouse efeito linear $(\mathrm{P}<0,01)$ dos níveis de casca de café sobre os teores de FDN das silagens, estimando-se redução de $0,31 \%$ no teor de FDN por unidade de casca adicionada. Estes decréscimos podem ser explicados pelo menor teor de FDN da casca em relação ao do capim-elefante, e pela menor produção de efluente, observado visualmente, nas silagens com casca. A redução na concentração de FDN de dietas contendo alta proporção de volumosos pode contribuir para aumentar o consumo de MS e ao mesmo tempo aumentar a densidade energética da ração de ruminantes (Jung \& Allen, 1995). Ao comparar os teores de FDN do capim no momento da ensilagem com a silagem sem casca, verificaram-se valores de 69,6 e $72,9 \%$, respectivamente. Esta diferença pode ser explicada pela perda de componentes solúveis da matéria seca (McDonald, 1981), aumentando a concentração de componentes da fração fibrosa.

A análise de regressão indicou efeito quadrático $(\mathrm{P}<0,01)$ dos níveis de casca de café sobre os teores de FDA das silagens, estimando-se valor mínimo de 41,60 para o nível de $20,09 \%$ de casca de café. O comportamento dos valores de FDA estimado pela equação é mostrado na Figura 3.

A redução nos teores de FDA das silagens, com a inclusão de até $20,09 \%$ de casca de café, pode ter ocorrido em função de uma resposta direta dos menores teores de FDN registrados na casca de café quando comparado ao capim-elefante no momento da ensilagem. Já os aumentos estimados nos teores de FDA das silagens com níveis superiores a $20,09 \%$ de casca de café podem ser explicados, em parte, pelos acréscimos nos teores de lignina das silagens com casca de café. Os valores médios e as equações de regressão da hemicelulose e lignina são mostrados na Tabela 3. Semelhantemente ao que ocorreu com a FDN, ao se compararem os teores de FDA, verificaram-se maiores valores para a silagem sem adição de casca $(46,61 \%)$ em relação ao capim no momento da ensilagem $(43,52 \%)$.

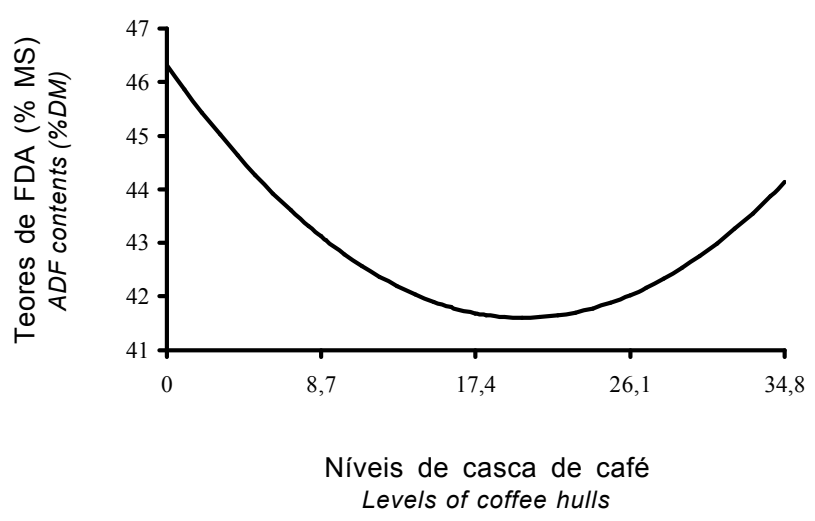

Figura 3 - Estimativa dos teores de fibra em detergente ácido nas silagens em função de diferentes níveis de casca de café.

Figure 3 - Estimate of acid detergent fiber (ADF) contents in function of the levels coffee hulls in the elephantgrass silages. 
Ao se proceder ao estudo da regressão, verificou-se efeito linear $(\mathrm{P}<0,01)$ dos níveis de casca de café sobre a DIVMS das silagens, estimando-se decréscimo de $0,14 \%$ no valor da DIVMS por unidade de casca de café adicionada. Os valores médios estimados pela equação foram de 64,$48 ; 63,24 ; 62,00 ; 60,77$ e $59,53 \%$ para os níveis de $0 ; 8,7 ; 17,4 ; 26,1$ e $34,8 \%$ de casca de café, respectivamente.

Mesmo com diminuição da DIVMS de 64,5 para $62,0 \%$ ao adicionar $26,1 \%$ de casca de café, este resultado pode ser considerado bom, por aproximar-se de $66,5 \%$, valor registrado para o capim no momento da ensilagem. Cabe ressaltar também que apesar da DIVMS da silagem sem aditivo ter alcançado valor superior às demais, esta pelo fato de ter apresentado forte odor desagradável, típico da ocorrência de fermentações indesejáveis e alta incidência de bolores foi considerada imprópria para o consumo animal.

\section{Conclusões}

A casca de café mostrou-se eficiente em aumentar o teor de MS da silagem de capim-elefante contribuindo para a produção de silagens com maiores disponibilidade de nitrogênio e menores teores de FDN quando comparado à silagem de capim sem casca.

A adição de casca de café no nível de 17,4 kg/100 $\mathrm{kg}$ de forragem fresca, ensilada com alto teor de umidade, garantiu a produção de silagens com bom valor nutritivo.

\section{Literatura Citada}

FERRARI JR., E.; LAVEZZO, W. Qualidade da silagem de capim-elefante (Pennisetum purpureum Schum.) emurchecido ou acrescido de farelo de mandioca. Revista Brasileira de Zootecnia, v.30, n.5, p.1424-1431, 2001.

JUNG, H.G.; ALLEN, M.S. Characteristics of plant cell walls affecting intake and digestibility of forages by ruminants. Journal of Animal Science, v.73, n.9, p.2774-2790, 1995.

LAVEZZO, W. Silagem de capim-elefante. Informe Agropecuário, v.11, n.132, p.50-59, 1985.
LICITRA, G.; HERNANDEZ, T.M.; Van SOEST, P.J. Standardization of procedures for nitrogen fractionation of ruminant feeds. Animal Feed Science and Technology, v.57, n.4, p.347-358, 1996.

LOURES, D.R.S. Características do efluente e composição químico-bromatológica da silagem sob níveis de compactação e de umidade do capim-elefante (Pennisetum purpureum Schum.), cv. Cameroon. Viçosa, MG: Universidade Federal de Viçosa, 2000. 67p. Dissertação (Mestrado em Zootecnia) - Universidade Federal de Viçosa, 2000.

McDONALD, P. The biochemistry of silage. Chichester: John Wiley \& Sons, 1981. 218p.

ROTZ, C.A.; MUCK, R.E. Changes in forage quality during harvest and storage. In: National Conference on Forage Quality, Evaluation, and Utilization Held at University of Nebraska, Lincoln, 1994, p.828-868.

SILVA, D.J. Análise de alimentos: métodos químicos e biológicos. Viçosa, MG: Universidade Federal de Viçosa, 1990. $165 p$.

SOUZA, A.L.; GARCIA, R.; PEREIRA, O.G. et al. Composição químico-bromatológica da casca de café tratada com amônia anidra e sulfeto de sódio. Revista Brasileira de Zootecnia, v.30, n.3, p.983-992, 2001. suplemento 1 ,

TOSI, H.; RODRIGUES, L.R.A.; JOBIM, C.C. et al. Ensilagem do capim-elefante cv. Mott sob diferentes tratamentos. Revista da Sociedade Brasileira de Zootecnia, v.24, n.6, p.909-916, 1995.

TOSI, P.; MATTOS, W.R.S.; TOSI, H. et al. Avaliação do capim-elefante (Pennisetum purpureum Scum.) Cultivar Taiwan A-148, ensilado com diferentes técnicas de redução de umidade. Revista Brasileira de Zootecnia, v.28, n.5, p.947-954, 1999.

UNIVERSIDADE FEDERAL DE VICOSA - UFV. SAEG Sistema de análises estatísticas e genéticas. Versão 7.1 . Viçosa, MG: 1997. 150p. (Manual do usuário).

Van SOEST, P.J.; MASON, V.C. The influence of Mallard reaction upon the nutritive value of fibrous feeds. Animal Feed Science and Technology, v.32, n.1/3, p.45-53, 1991.

WILKINSON, J.M. Additives for ensiled temperate forage crops. In. REUNIÃO ANUAL DA SOCIEDADE BRASILEIRA DE ZOOTECNIA, 35., 1998, Botucatu. Anais... Botucatu: Sociedade Brasileira de Zootecnia, 1998. p.73-108

Recebido em: 25/06/02

Aceito em: 29/11/02 